\title{
Association between Serum Sodium Level and Severity of Complications in Liver Cirrhosis
}

\author{
Authors \\ *Ahmed Amin Ibrahim MD, Waleed Mohammad El Nabawy MD, \\ Mohamed Ibrahim Atta MD., Mohamed Nabil Salem MD, Mahmoud Naiem \\ Beni Suef University
}

\begin{abstract}
Background: Cirrhosis is the end result of chronic liver injury from a variety of causes. It is well recognized in many studies that complicated liver cirrhosis is accompanied by hyponatremia. Hyponatremia is a common abnormal finding in approximately 57\% of hospitalized patients with chronic liver disease and in $40 \%$ of outpatients with liver disease.

Aim of work: The purpose of the present work is to study the association between serum sodium level and the severity of complications in liver cirrhosis

Subjects and Methods: One hundred patients with complicated liver cirrhosis will be randomly selected from Internal Medicine department and classified according to Child-Pugh class and one fifty uncomplicated chronic liver disease individuals served as a control, Patients with hepatocellular carcinoma, any other malignancy or other major organ failure presented at admission and during the follow up, also patients taking antiviral drugs were excluded. Complications included ascites, hepatic encephalopathy, spontaneous bacterial peritonitis, hepatorenal syndrome, esophageal and gastric varices, were classified based on severity. All patients and controls in this study were subjected to: Complete history taking, Complete Physical examination_All Laboratory routine investigations, Abdominal Ultrasound and upper endoscopy. Patient were classified into groups according the previous Child Pugh classification as 5 patients of the complicated group (5.0\%) were Child-Pugh A, 34 were B (34\%) and 61 were C (61\%), while in the control group 50 persons were child A (100) and no one was classified as child $B$ or $C$.

Results: Assessing the serum level among the two groups revealed a highly significant difference between the two studied groups and a significant positive correlation was observed between serum sodium level and ChildPugh score, abdominal ascites, encephalopathy and SBP, HRS, however, no correlation was detected between serum sodium level and, esophegeal varices and fundal varices.

Conclusion: There is conclusive evidence that Hyponatremia, especially serum levels $<130 \mathrm{mmol} / \mathrm{L}$, may indicate the existence of severe complications associated with liver cirrhosis esp. ascites, HRS, SBP and hepatic encephalopathy.

Keywords: liver cirrhosis, Child-Pugh, serum sodium, Ascites, Varices.
\end{abstract}

\section{Introduction}

Cirrhosis is defined histologically as a diffuse hepatic process characterized by fibrosis and the conversion of normal liver architecture into structurally abnormal nodules. The progression of liver injury to cirrhosis may occur over weeks to years. Cirrhosis resulted in 1.2 million deaths in 2013, up from 0.8 million deaths in 1990. Of these, 
alcohol caused 384,000, hepatitis C caused 358,000 , and hepatitis B caused 317,000.

Cirrhosis is the 12th leading cause of death in the United States, accounting for nearly 32,000 deaths each year. More men die of cirrhosis than women. $^{(1)(2)}$

Egypt holds a unique position in the epidemiology of hepatitis and liver cirrhosis. The highest prevalence of hepatitis C virus (15\%-20\%) has been reported from Egypt. It has successfully implemented the hepatitis B virus vaccine and boasted $95 \%-100 \%$ coverage. Hyponatremia is a common abnormal finding in approximately $57 \%$ of hospitalized patients with chronic liver disease and in $40 \%$ of outpatients with liver disease. Intractable ascites, severe hyponatremia, and decreased arterial pressure are clinical findings seen in patients with advanced cirrhosis. These conditions occur as a result of high serum levels of renin/aldosterone owing to portal hypertension, a decreased vascular response to vasoactive drugs, and a reduced solute-free water clearance. ${ }^{(3)(4)}$

Fibrosis as a precursor of cirrhosis is a pivotal pathological process in the evolution of all chronic liver diseases to cirrhosis. At present, effective strategies to treat liver cirrhosis are still lacking, partially because of a poor understanding of the molecular mechanisms leading to cirrhosis. Thus, a better understanding of the pathogenesis of liver cirrhosis would facilitate the development of more effective treatment options. Cirrhosis is an advanced stage of liver fibrosis that is accompanied by distortion of the hepatic vasculature. The pathological hallmark of cirrhosis is the development of scar tissue that replaces normal parenchyma. This scar tissue blocks the portal flow of blood through the organ therefore disturbing normal function. Recent research shows the pivotal role of the stellate cell, a cell type that normally stores vitamin A, in the development of cirrhosis. Damage to the hepatic parenchyma (due to inflammation) leads to activation of the stellate cell, which increases fibrosis (through production of myofibroblasts) and obstructs blood flow in the circulation. $^{(5)}$
The natural history of cirrhosis can be divided into a preclinical and a subsequent clinical phase .The preclinical phase is usually prolonged over several years; once clinical events occur, such as, ascites, encephalopathy, variceal bleeding or the development of hepatocellular carcinoma the remaining course of the disease is much shorter and usually fatal. For the liver cirrhosis there is still no curable treatment available except for liver transplantation. ${ }^{(6)}$

The most common complications are: Gastrointestinal hemorrhage, ascites, encephalopathy, bacterial infections, renal failure, hepatocellular carcinoma and hepatic failure Certain reversible components of cirrhosis have been indicated where significant histological improvement have occurred with regression of cirrhosis but complete resolution with a return to normal architecture seems unlikely ${ }^{(7)}$

According to several studies, hyponatremia occurring as a result of a reduced solute-free water clearance was a key prognostic factor in patients with liver cirrhosis ${ }^{(8)}$.

\section{Aim of the Work}

The aim of the present work is to study the association between serum sodium level and the severity of complications in liver cirrhosis as a prognostic factor.

\section{Subjects and Methods}

150 patients were enrolled in the study, 100 patients of them with complicated liver cirrhosis and 50 patients with uncomplicated liver cirrhosis served as control, Patients with liver cirrhosis [diagnosis was limited to cases with approved liver cirrhosis by clinical findings, laboratory and ultrasonography] were randomly selected from Beni-suef university hospital from January 2015 to June 2015 based on severity of complications at the time of admission. Complications included ascites, hepatic encephalopathy, spontaneous bacterial peritonitis, hepatorenal syndrome, esophageal and gastric varices.

Ascites, hepatic encephalopathy, and esophageal varices were classified based on severity. 
Ascites was classified as follows: grade I, ascites observed on imaging study but presence is unclear on physical examination; grade II, ascites easily recognized on gross examination and palpation; and grade III, severe abdominal distention concurrently present on gross examination and large-volume paracentesis performed for therapeutic purposes.

Cases of hepatic encephalopathy higher than grade III based on the West Haven criteria were determined to be severe, and other cases were all determined to be mild. Endoscopy was done for all patients during the last 3 months either as an inpatient or outpatient procedure.

Esophageal varices were classified by size and shape based on endoscopic findings, as follows: grade I: a linear, small sized varix, grade II: a beaded, medium sized varix, grade III, a nodular, large varix and grade IV varix: large varix occupying more than one third of the esophageal lumen ${ }^{(9)}$.

\section{Inclusion Criteria}

Patients with liver cirrhosis due to viral cause [HCV or HBV], HCV diagnosed by positive HCV antibody, HBV diagnosed by positive HBV surface antigen, other causes of liver cirrhosis were classified as others, and complication of liver cirrhosis as ascites ,hepatic encephalopathy, esophegeal and fundal varices, SBP and hepatorenal syndrome were included in the study.

\section{Exclusion Criteria}

Patients with hepatocellular carcinoma, other malignancy or other major organ failure presented at admission and during the follow up, also patients taking antiviral drugs.

\section{Methodology}

All patients and controls in this study were subjected to:

\section{Complete history taking.}

\section{Complete Physical examination.}

Laboratory investigations including:

- Complete blood picture (CBC).

- Serum sodium and potassium.

- Liver function tests (Serum aspartate transaminase (AST), alanine transaminase
(ALT), total and direct bilirubin, prothrombin time and concentration, serum albumin.

- Viral markers, (HBsAg, Anti HCVAb).

\section{Abdominal Ultrasound and upper endoscopy} Child- Pugh scoring

\begin{tabular}{|l|c|c|c|}
\hline Clinical variable & $\mathbf{1}$ point & $\mathbf{2}$ points & $\mathbf{3}$ points \\
\hline Encephalopathy & None & Stages 1-2 & Stages 3-4 \\
\hline Ascites & Absent & Slight & Moderate \\
\hline Bilirubin (mg/dL) & $<2$ & $2-3$ & $>3$ \\
\hline Albumin (g/dL) & $>3.5$ & $2.8-3.5$ & $<2.8$ \\
\hline $\begin{array}{l}\text { Prothrombin } \\
\text { time(seconds } \\
\text { prolonged or INR) }\end{array}$ & $<4$ s or INR & $\begin{array}{c}4-6 \text { s or INR } \\
<1.7\end{array}$ & $\begin{array}{c}>6 \text { s or INR } \\
>2.3\end{array}$ \\
\hline
\end{tabular}

Child-Turcotte-Pugh Scoring System for Cirrhosis (Child Class $\mathrm{A}=5-6$ points, Child Class $\mathrm{B}=7-9$ points, Child Class $\mathrm{C}=10-15$ points).

Patient were classified into groups according the previous Child Pugh classification as 5 patients of the complicated group (5.0\%) were Child-Pugh A, 34 were B (34\%) and 61 were C $(61 \%)$, while in the control group 50 persons were child A (100) and no one was classified as child B or $\mathrm{C}$.

\section{Statistics}

Data were statistically described in terms of mean \pm standard deviation ( \pm SD), or frequencies (number of cases) and percentages when appropriate. Comparison of numerical variables between the study groups was done using Student $\mathrm{t}$ test for independent samples. For comparing categorical data, Chi square $(\chi 2)$ test was performed. Exact test was used instead when the expected frequency is less than 5 . $\mathrm{P}$ values less than 0.05 was considered statistically significant. All statistical calculations were done using computer program SPSS (Statistical Package for the Social Science; SPSS Inc., Chicago, IL, USA) version 15 for Microsoft Windows.

\section{Results}

This study was conducted on one hundred cirrhotic complicated patients with age ranging 
from 27 to 76 years (mean \pm SD of $52.33 \pm 12.35$ ) and fifty uncomplicated liver cirrhosis served as controls with age ranging from 24 to 76 years (mean \pm SD of $52.72 \pm 12.146$ ); $\mathrm{P}=0.796$.

67 of the cirrhotic complicated group were males (67\%) while 33 were females (33\%), and 33 of the control group were males $(66 \%)$ while 17 were females $(34 \%)$

Table (1) Mean age of the two studied groups

\begin{tabular}{|l|c|c|}
\hline & $\begin{array}{c}\text { Cirrhotic \& } \\
\text { complicated }(\mathbf{n}=\mathbf{1 0 0})\end{array}$ & $\begin{array}{c}\text { Control group } \\
(\mathbf{n}=\mathbf{5 0})\end{array}$ \\
\hline Age (Years) & $52.33 \pm 12.35$ & $52.72 \pm 12.146$ \\
\hline
\end{tabular}

Table (2) Frequency distribution of sex among the two studied groups

\begin{tabular}{|l|l|l|}
\hline & Male & Female \\
\hline Cirrhotic complicated group $(\mathbf{n = 1 0 0})$ & $67(67 \%)$ & $33(33 \%)$ \\
\hline Control group $(\mathbf{n = 5 0})$ & $33(66 \%)$ & $17(34 \%)$ \\
\hline
\end{tabular}

\section{Descriptive statistics according to the type and degree of complication}

1. Among patients with ascites 23 patients (25.3\%) were grade I, 42 patients $(46.2 \%)$ were grade II, 26 were grade III $(28.5 \%)$.
2. Among patients with varices 7 patients (29.2\%) had esophageal varices grade I, 12 patients $(50 \%)$ grade II, 3 patients $(12.5 \%)$ grade III and, no patients had grade IV esophegeal varices, and 2 patients $(8.3 \%)$ had fundal varices.

3. Among patients with encephalopathy 9 (60\%) patients had mild encephalopathy and $6(40 \%)$ patients had severe encephalopathy.

4. Among patients with complicated cirrhosis $12(12.0 \%)$ patients had spontaneous bacterial peritonitis.

5. Among patients with complicated cirrhosis $12(12 \%)$ had hepatorenal syndrome 4 of them type 1 and 8 type 2 .

Table (3) degree of ascites in relation to the study group.

\section{Ascites group}

\begin{tabular}{|c|c|c|c|}
\hline & \multirow{4}{*}{$\begin{array}{c}\text { Group } \\
\text { Cases } \\
23\end{array}$} \\
\hline & & & \\
\hline & & & \\
\hline \multirow[t]{8}{*}{ Ascites } & \multirow{2}{*}{ grade I } & Number & \\
\hline & & $\%$ within Group & $25.3 \%$ \\
\hline & \multirow[t]{2}{*}{ grade II } & Number & 42 \\
\hline & & $\%$ within Group & $46.2 \%$ \\
\hline & \multirow[t]{2}{*}{ grade III } & Number & 26 \\
\hline & & $\%$ within Group & $28.5 \%$ \\
\hline & \multirow[t]{2}{*}{ Total } & Number & 91 \\
\hline & & $\%$ within Group & $100.0 \%$ \\
\hline
\end{tabular}

Table (4) varices in relation to the study group.

Varices group

\begin{tabular}{|c|c|c|c|}
\hline & & & \multirow{2}{*}{ Group } \\
\hline & & & \\
\hline & & & Cases \\
\hline \multirow[t]{8}{*}{ Varices } & \multirow[t]{2}{*}{ Grade I } & Number & 7 \\
\hline & & $\%$ within Group & $29.2 \%$ \\
\hline & \multirow[t]{2}{*}{ Grade II } & Number & 12 \\
\hline & & $\%$ within Group & $50 \%$ \\
\hline & \multirow[t]{2}{*}{ Grade III } & Number & 3 \\
\hline & & $\%$ within Group & $12.5 \%$ \\
\hline & \multirow[t]{2}{*}{ fundal } & Number & 2 \\
\hline & & $\%$ within Group & $8.3 \%$ \\
\hline \multirow{2}{*}{\multicolumn{2}{|c|}{ Total }} & Number & 24 \\
\hline & & $\%$ within Group & $100.0 \%$ \\
\hline
\end{tabular}


Table (5) encephalopathy in relation to the study group

Encephalopathy group

\begin{tabular}{|c|c|c|c|}
\hline & \multirow{3}{*}{$\begin{array}{c}\text { Group } \\
\text { Cases }\end{array}$} \\
\hline & & & \\
\hline & & & \\
\hline \multirow[t]{4}{*}{ Encephalopathy } & \multirow[t]{2}{*}{ mild } & Number & 9 \\
\hline & & $\%$ within Group & $60 \%$ \\
\hline & \multirow[t]{2}{*}{ severe } & Number & 6 \\
\hline & & $\%$ within Group & $40 \%$ \\
\hline \multirow[t]{3}{*}{ Total } & & Number & 15 \\
\hline & & $\%$ within Group & $100.0 \%$ \\
\hline & & $\%$ within Group & $100.0 \%$ \\
\hline
\end{tabular}

Table (6) SBP in relation to the study group.

SPB group

\begin{tabular}{|c|c|c|c|}
\hline & \multirow{3}{*}{$\begin{array}{c}\text { Group } \\
\text { Cases }\end{array}$} \\
\hline & & & \\
\hline \multirow{5}{*}{ SPB } & \multirow{3}{*}{ No } & & \\
\hline & & Number & 88 \\
\hline & & $\%$ within Group & $88 \%$ \\
\hline & \multirow[t]{2}{*}{ Yes } & Number & 12 \\
\hline & & $\%$ within Group & $12 \%$ \\
\hline \multirow{2}{*}{\multicolumn{2}{|c|}{ Total }} & Number & 100 \\
\hline & & $\%$ within Group & $100.0 \%$ \\
\hline
\end{tabular}

Table (7) HRS in relation to the study group.

HRS group

\begin{tabular}{|c|c|c|c|}
\hline & & & \multirow{2}{*}{ Group } \\
\hline & & & \\
\hline & & & Cases \\
\hline \multirow[t]{8}{*}{ HRS } & \multirow[t]{2}{*}{ No } & Number & 88 \\
\hline & & $\%$ within Group & $88 \%$ \\
\hline & \multirow[t]{2}{*}{ type 1} & Number & 4 \\
\hline & & $\%$ within Group & $4 \%$ \\
\hline & \multirow[t]{2}{*}{ type 2} & Number & 8 \\
\hline & & $\%$ within Group & $8 \%$ \\
\hline & \multirow[t]{2}{*}{ Total } & Number & 100 \\
\hline & & $\%$ within Group & $100.0 \%$ \\
\hline
\end{tabular}

\section{Serum Sodium}

Serum sodium level in complicated group varied from $117 \mathrm{mmol} / \mathrm{l}$ to $146 \mathrm{mmol} / \mathrm{l}$ (mean $\pm \mathrm{SD}$ of $132.23 \pm 5.892)$ while serum sodium in control group varied from $128 \mathrm{mmol} / \mathrm{l}$ to $145 \mathrm{mmol} / \mathrm{l}$ (mean \pm SD of $138.36 \pm 3.563$ ).

As regards serum sodium difference between control and complicated group it was found that the difference between the 2 groups is statistically significance.

$\mathrm{P}=0.0001$ i.e. $<0.05$

Table (8) $\mathrm{p}$ value of serum sodium

\begin{tabular}{|l|c|c|c|c|}
\hline Serum & case & control & $\mathrm{P}$ & $t$ test \\
sodium & 132.23 & 138.36 & value $=0.0001$ & $=9.569$ \\
\hline
\end{tabular}

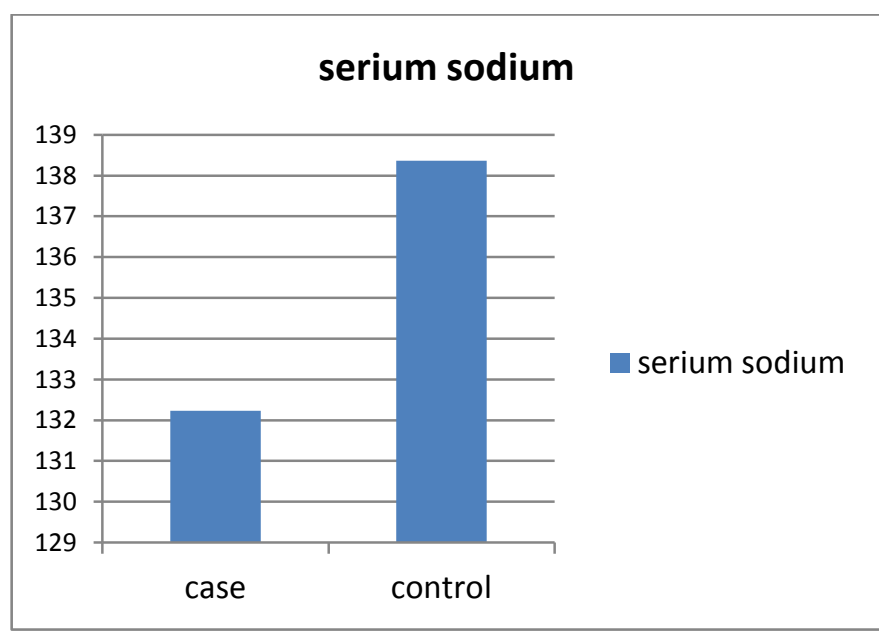

Fig (1) mean serum sodium in the two studied group. 
Serum sodium was classified in our study into 3 groups:
1) $<130$
2) $130-135$
3) $>135$

\section{In complicated liver cirrhosis group}

1) 29 patients $(29.0 \%)$ had serum sodium less than $130 \mathrm{mmol} / \mathrm{l}$.

2) 46 patients $(46.5 \%)$ had serum sodium (130-135mmol/l).

3) 25 patients $(24.5 \%)$ had serum sodium more than $135 \mathrm{mmol} / \mathrm{l}$.

In uncomplicated liver cirrhosis (control) group:

1) 1 patients $(2.0 \%)$ had s.sodium less than $130 \mathrm{mmol} / \mathrm{l}$.

2) 7 patients (14.0\%) had s.sodium (130$135 \mathrm{mmol} / \mathrm{l})$.

3) 42 patients $(84.0 \%)$ had s.sodium more than $135 \mathrm{mmol} / \mathrm{l}$.

$P$ value 0.000 i.e. $<0.05$ which is found to be highly significant correlation.

Table (9) serum sodium level in relation to the study group.

\begin{tabular}{|c|c|c|c|c|c|}
\hline \multicolumn{6}{|c|}{ s.Sodium } \\
\hline & & & \multicolumn{2}{|c|}{ Group } & \multirow[t]{2}{*}{ Total } \\
\hline & & & Controls & Cases & \\
\hline \multirow{6}{*}{$\begin{array}{l}\text { s.Sodiu } \\
\text { m }\end{array}$} & \multirow[t]{2}{*}{$<130$} & Number & 1 & 29 & 30 \\
\hline & & $\begin{array}{c}\% \\
\text { within } \\
\text { Group }\end{array}$ & $2.0 \%$ & $29.0 \%$ & $20.0 \%$ \\
\hline & \multirow{2}{*}{$\begin{array}{l}130- \\
135\end{array}$} & Number & 7 & 46 & 53 \\
\hline & & $\begin{array}{c}\% \\
\text { within } \\
\text { Group }\end{array}$ & $14.0 \%$ & $46.0 \%$ & $35.3 \%$ \\
\hline & \multirow[t]{2}{*}{$>135$} & Number & 42 & 25 & 67 \\
\hline & & $\begin{array}{c}\% \\
\text { within } \\
\text { Group }\end{array}$ & $84.0 \%$ & $25.0 \%$ & $44.7 \%$ \\
\hline \multirow{2}{*}{\multicolumn{2}{|c|}{ Total }} & Number & 50 & 100 & 150 \\
\hline & & $\begin{array}{c}\% \\
\text { within } \\
\text { Group }\end{array}$ & $100.0 \%$ & $\begin{array}{c}100.0 \\
\%\end{array}$ & $\begin{array}{c}100.0 \\
\%\end{array}$ \\
\hline
\end{tabular}

\begin{tabular}{|l|l|l|}
\hline \multicolumn{3}{|l|}{ Chi-Square Tests } \\
\hline & Value & $\mathrm{p}$ value \\
\hline $\begin{array}{l}\text { Pearson } \\
\text { Chi-Square }\end{array}$ & 93.75 & 0.000 \\
\hline $\begin{array}{l}\text { N of Valid } \\
\text { Cases }\end{array}$ & 300 & \\
\hline
\end{tabular}

Fig (2) Frequency distribution of serum sodium level in both studied groups.

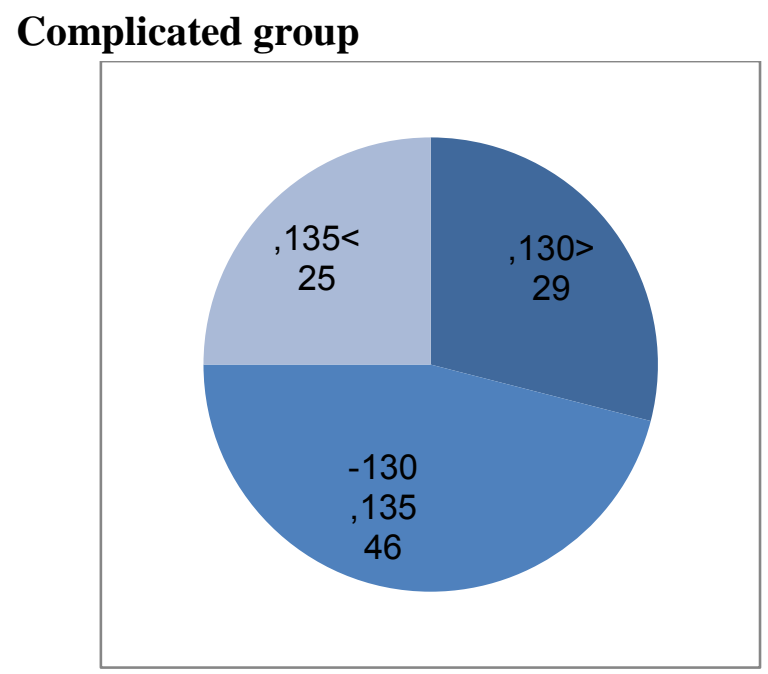

\section{Control group}

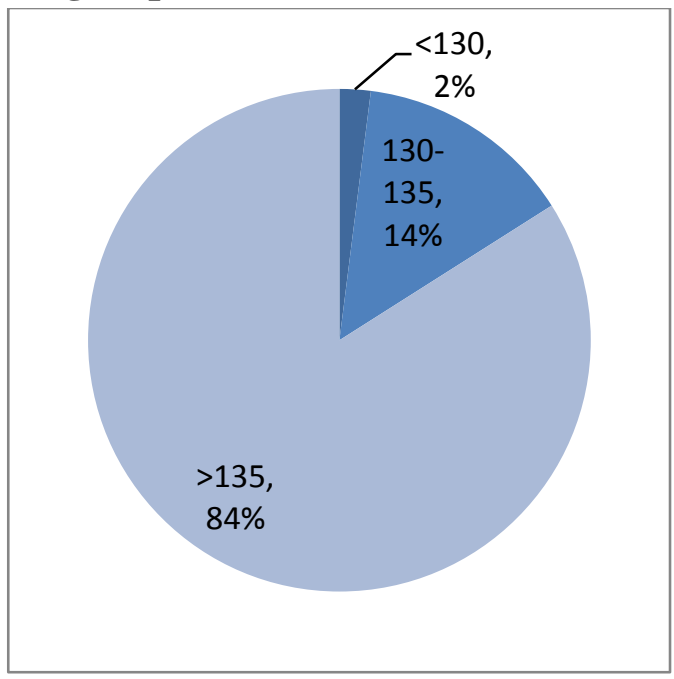

\section{s.sodium level in relation to child score}

1) Child A: no patients $<130 \mathrm{mmol} / \mathrm{l}$

1 patients $130-135 \mathrm{mmol} / \mathrm{l}$

7 patients $>135 \mathrm{mmol} / \mathrm{l}$

2) Child B: 10 patients $<130 \mathrm{mmol} / \mathrm{l}$

19 patients $130-135 \mathrm{mmol} / \mathrm{l}$

5 patients $>135 \mathrm{mmol} / \mathrm{l}$

3) Child C: 19 patients $<130 \mathrm{mmol} / \mathrm{l}$

26 patients $130-135 \mathrm{mmol} / \mathrm{l}$

16 patients $>135 \mathrm{mmol} / \mathrm{l}$

$\mathrm{P}$ value of 0.004 i.e. $<0.05$ which is found to have a significant correlation 
Table (10) child scoring system in relation to the study group.

\begin{tabular}{|c|c|c|c|c|c|c|}
\hline \multicolumn{7}{|c|}{$\begin{array}{l}\text { Child classification } \\
\text { and s.Sodium }\end{array}$} \\
\hline & & & \multicolumn{3}{|c|}{ s.Sodium } & \multirow[t]{2}{*}{ Total } \\
\hline & & & $<130$ & $130-135$ & $>135$ & \\
\hline \multirow{6}{*}{$\begin{array}{l}\text { Chil } \\
\text { d }\end{array}$} & \multirow[t]{2}{*}{$\mathrm{A}$} & Number & 0 & 1 & 4 & 5 \\
\hline & & $\begin{array}{l}\% \text { within } \\
\text { s.Sodium }\end{array}$ & $0.0 \%$ & $2.2 \%$ & $16 \%$ & $5 \%$ \\
\hline & \multirow[t]{2}{*}{ B } & Number & 10 & 19 & 5 & 34 \\
\hline & & $\begin{array}{l}\% \text { within } \\
\text { s.Sodium }\end{array}$ & $\begin{array}{c}34.5 \\
\%\end{array}$ & $41.3 \%$ & $20 \%$ & $34 \%$ \\
\hline & \multirow[t]{2}{*}{$\mathrm{C}$} & Number & 19 & 26 & 16 & 61 \\
\hline & & $\begin{array}{l}\% \text { within } \\
\text { s.Sodium }\end{array}$ & $\begin{array}{c}65.5 \\
\%\end{array}$ & $56.5 \%$ & $64 \%$ & $61 \%$ \\
\hline \multirow{2}{*}{\multicolumn{2}{|c|}{ Total }} & Number & 29 & 46 & 25 & 100 \\
\hline & & $\begin{array}{l}\% \text { within } \\
\text { s.Sodium }\end{array}$ & $\begin{array}{c}100.0 \\
\%\end{array}$ & $100.0 \%$ & $100.0 \%$ & $\begin{array}{c}100.0 \\
\%\end{array}$ \\
\hline
\end{tabular}

\begin{tabular}{|l|c|c|}
\hline \multicolumn{3}{|l|}{ Chi-Square Tests } \\
\hline & Value & p value \\
\hline Pearson Chi-Square & 15.155 & 0.004 \\
\hline N of Valid Cases & 200 & \\
\hline
\end{tabular}
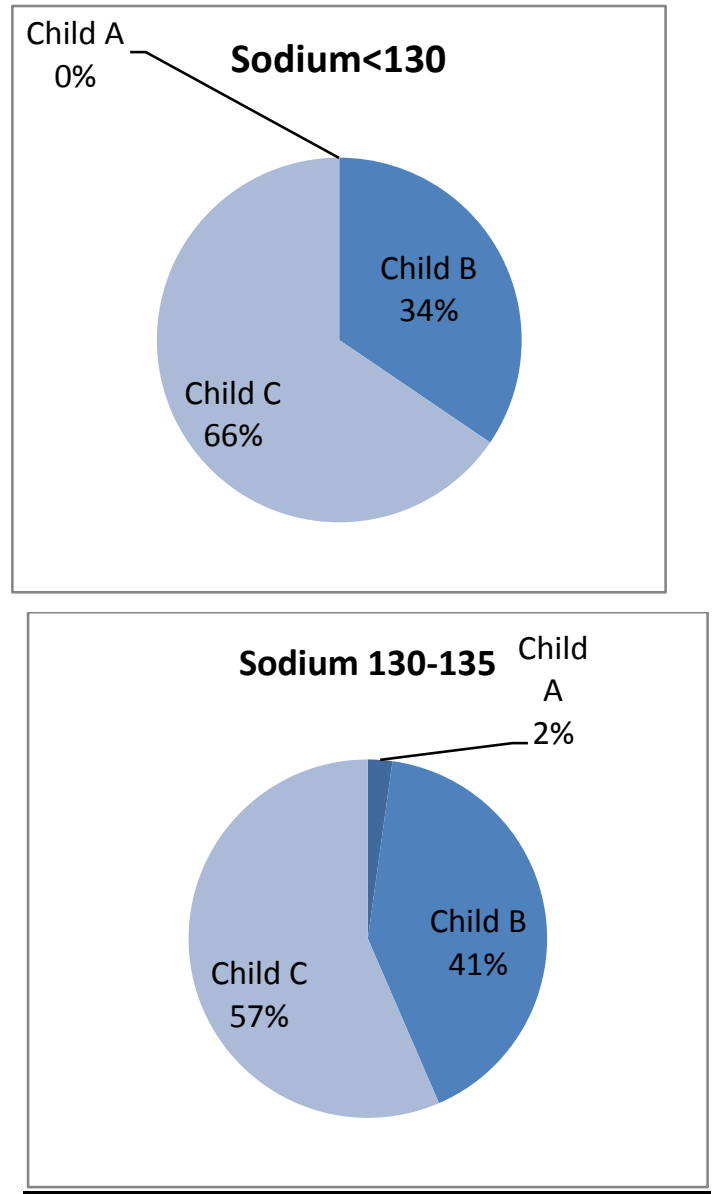

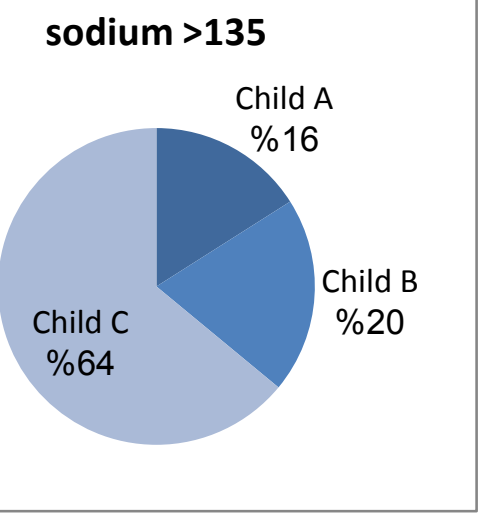

Figure (3) frequency distribution of serum sodium in different child scores.

s.sodium in relation to the presence and the degree of ascites:

\section{1) Patients who had no ascites}

One patient had serum sodium $<130 \mathrm{mmol} / \mathrm{l}$. 3 patients had serum sodium $130-135 \mathrm{mmol} / \mathrm{l}$. 5 patients had serum sodium $>135 \mathrm{mmol} / \mathrm{l}$.

\section{2) Ascites grade I:}

2 patients had serum sodium $<130 \mathrm{mmol} / \mathrm{l}$. patients had serum sodium 130-135 mol/l. 10 patients had serum sodium $>135 \mathrm{mmol} / \mathrm{l}$.

\section{3) Ascites grade II :}

12 patients had serum sodium $<130 \mathrm{mmol} / \mathrm{l}$. patients had serum sodium $130-135 \mathrm{mmol} / \mathrm{l}$. 8 patients had serum sodium $>135 \mathrm{mmol} / \mathrm{l}$.

\section{4) Ascites grade III:}

14 patients had serum sodium $<130 \mathrm{mmol} / 1$. 10 patients had serum sodium $130-135 \mathrm{mmol} / \mathrm{l}$. 2 patients had serum sodium $>135 \mathrm{mmol} / \mathrm{l}$. $P$ value $=0.0001[<0.05]$ which is found to be highly significant correlation. 
Table (11) serum sodium in different degrees of ascites.

\begin{tabular}{|c|c|c|c|c|c|c|}
\hline \multicolumn{7}{|c|}{$\begin{array}{l}\text { Ascites group } \\
\text { and s.Sodium }\end{array}$} \\
\hline & & & \multicolumn{3}{|c|}{ s.Sodium } & \multirow[t]{2}{*}{ Total } \\
\hline & & & $<130$ & $\begin{array}{l}130- \\
135\end{array}$ & $>135$ & \\
\hline \multirow{6}{*}{$\begin{array}{l}\text { Asc } \\
\text { ites }\end{array}$} & \multirow[t]{2}{*}{ No } & Number & 1 & 3 & 5 & 9 \\
\hline & & $\begin{array}{l}\% \text { within } \\
\text { s.Sodium }\end{array}$ & $3.4 \%$ & $6.5 \%$ & $20 \%$ & $9 \%$ \\
\hline & \multirow[t]{2}{*}{ Grade 1} & Number & 2 & 11 & 10 & 23 \\
\hline & & $\begin{array}{l}\% \text { within } \\
\text { s.Sodium }\end{array}$ & $6.8 \%$ & $24 \%$ & $40 \%$ & $23 \%$ \\
\hline & \multirow[t]{2}{*}{ Grade 11} & Number & 12 & 22 & 8 & 42 \\
\hline & & $\begin{array}{l}\% \text { within } \\
\text { s.Sodium }\end{array}$ & $\begin{array}{c}41.4 \\
\%\end{array}$ & $47.8 \%$ & $32 \%$ & $42 \%$ \\
\hline
\end{tabular}

\begin{tabular}{|c|c|c|c|c|c|c|}
\hline \multirow{3}{*}{\begin{tabular}{l} 
Grade \\
\multirow{2}{*}{ 1ll }
\end{tabular}} & Number & 14 & 10 & 2 & 26 \\
\cline { 3 - 7 } & \% within & 48.4 & $21.7 \%$ & $8 \%$ & $26 \%$ \\
& s.Sodium & $\%$ & & & \\
\hline \multicolumn{2}{|l|}{ Total } & Number & 29 & 46 & 25 & 100 \\
\cline { 2 - 6 } & $\%$ within & 100.0 & 100.0 & 100.0 & 100.0 \\
& s.Sodium & $\%$ & $\%$ & $\%$ & $\%$ \\
\hline
\end{tabular}

\begin{tabular}{|l|c|c|}
\hline \multicolumn{3}{|l|}{ Chi-Square Tests } \\
\hline & Value & p value \\
\hline Pearson Chi-Square & 43.807 & 0.0001 \\
\hline
\end{tabular}

\begin{tabular}{|l|l|l|}
\hline Pearson Chi-Square & 43.807 & 0.0001 \\
\hline N of Valid Cases & 200 & \\
\hline
\end{tabular}
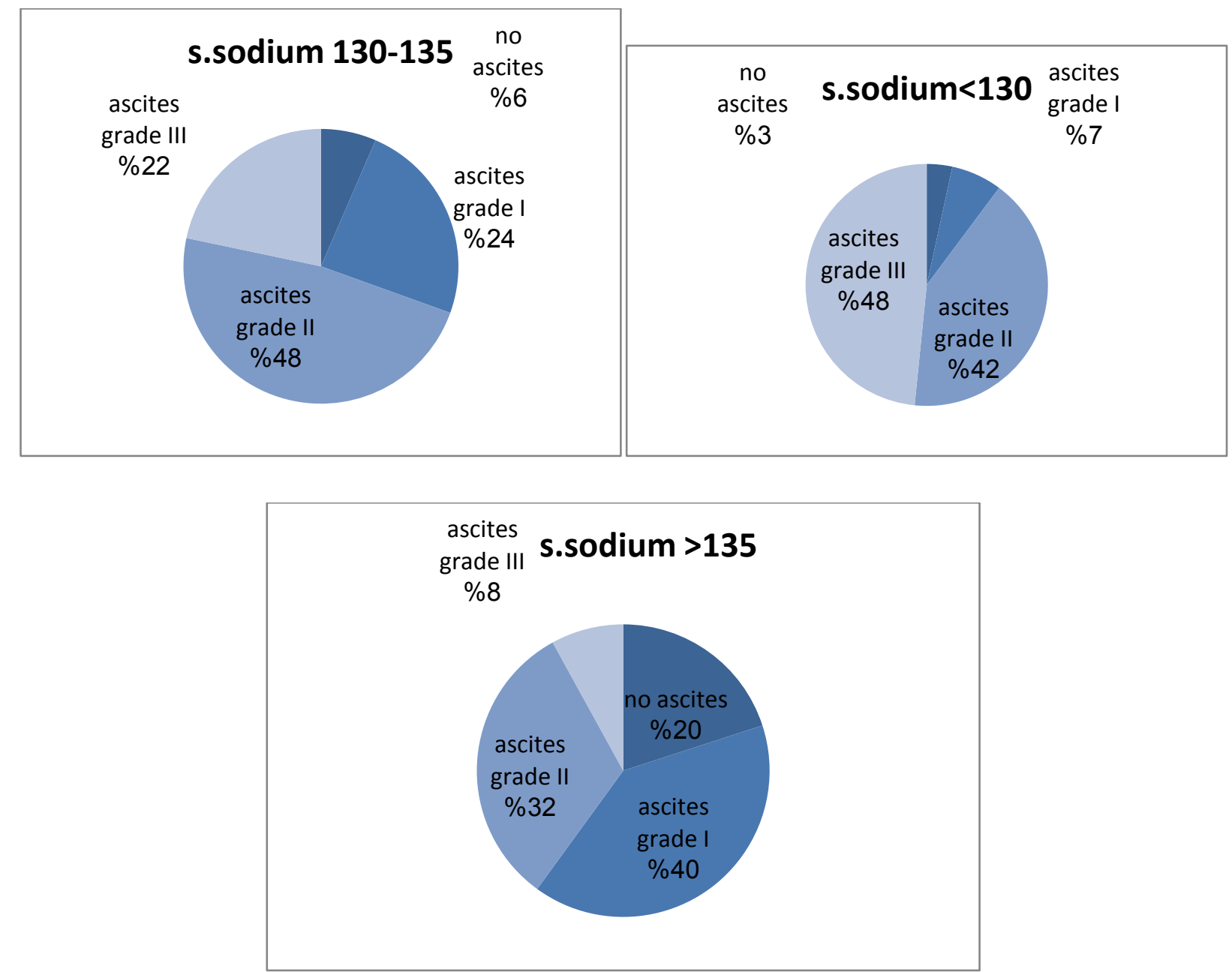

Figure (4) frequency distribution of serum sodium in different grades of ascites

Serum sodium in relation to esophageal and fundal varices:

\section{In the complicated group}

1. 7 cases with Esophageal varices grade I [ 2 cases with serum sodium $<130 \mathrm{mmol} / \mathrm{l}, 2$ cases with serum sodium $130-135 \mathrm{mmol} / \mathrm{l}$ and 3 cases with serum sodium $>135$ $\mathrm{mg} / \mathrm{dl}]$.
2. 12 cases with esophageal varices grade II [ 1 case with serum sodium $<130 \mathrm{mmol} / \mathrm{l}, 4$ cases with serum sodium $130-135 \mathrm{mmol} / \mathrm{l}$ and 7 cases with serum sodium $>135$ $\mathrm{mmol} / \mathrm{l}]$

3. 3 cases with esophageal varices grade III [ 1 case with serum sodium $<130 \mathrm{mmol} / \mathrm{l}, 1$ case with serum sodium $130-135 \mathrm{mmol} / 1$ 
and 1 case with serum sodium $>135$ $\mathrm{mmol} / \mathrm{l}]$.

4. 2 cases with fundal varices [one of them with serum sodium $130-135 \mathrm{mmol} / \mathrm{l}$ and the other case with serum sodium $>135$ $\mathrm{mmol} / \mathrm{l}$.

5. No cases with esophageal varices grade IV.

$P$ value $=0.871$ which has no significant correlation.

Table (12) serum sodium in relation to varices.

\begin{tabular}{|c|c|c|c|c|c|c|}
\hline \multicolumn{7}{|c|}{ Varices and s.Sodium } \\
\hline & & & \multicolumn{3}{|c|}{ s.Sodium } & \multirow{2}{*}{$\begin{array}{l}\text { Tot } \\
\text { al }\end{array}$} \\
\hline & & & $\begin{array}{l}< \\
130\end{array}$ & $\begin{array}{l}130 \\
- \\
135\end{array}$ & $\begin{array}{l}> \\
135\end{array}$ & \\
\hline \multirow[t]{8}{*}{ Varices } & \multirow{2}{*}{$\begin{array}{l}\text { Grad } \\
\text { e I }\end{array}$} & Number & 2 & 2 & 3 & 7 \\
\hline & & $\begin{array}{l}\% \text { within } \\
\text { s.Sodium }\end{array}$ & $\begin{array}{l}50 \\
\%\end{array}$ & $\begin{array}{l}25 \\
\%\end{array}$ & $25 \%$ & $\begin{array}{l}29.2 \\
\%\end{array}$ \\
\hline & \multirow{2}{*}{$\begin{array}{l}\text { Grad } \\
\text { e II }\end{array}$} & Number & 1 & 4 & 7 & 12 \\
\hline & & $\begin{array}{l}\% \text { within } \\
\text { s.Sodium }\end{array}$ & $\begin{array}{l}25 \\
\%\end{array}$ & $\begin{array}{l}50 \\
\%\end{array}$ & $\begin{array}{l}58.4 \\
\%\end{array}$ & $\begin{array}{l}50 \\
\%\end{array}$ \\
\hline & \multirow{2}{*}{$\begin{array}{l}\text { Grad } \\
\text { e III }\end{array}$} & Number & 1 & 1 & 1 & 3 \\
\hline & & $\begin{array}{l}\% \text { within } \\
\text { s.Sodium }\end{array}$ & $\begin{array}{l}25 \\
\%\end{array}$ & $\begin{array}{l}12.5 \\
\%\end{array}$ & $\begin{array}{l}8.3 \\
\%\end{array}$ & $\begin{array}{l}12.5 \\
\%\end{array}$ \\
\hline & \multirow{2}{*}{$\begin{array}{l}\text { funda } \\
1\end{array}$} & Number & 0 & 1 & 1 & 2 \\
\hline & & $\begin{array}{l}\% \text { within } \\
\text { s.Sodium }\end{array}$ & $\begin{array}{l}0.0 \\
\%\end{array}$ & $\begin{array}{l}12.5 \\
\%\end{array}$ & $\begin{array}{l}8.3 \\
\%\end{array}$ & $\begin{array}{l}8.3 \\
\%\end{array}$ \\
\hline \multirow{2}{*}{\multicolumn{2}{|c|}{ Total }} & Number & 4 & 8 & 12 & 24 \\
\hline & & $\begin{array}{l}\% \text { within } \\
\text { s.Sodium }\end{array}$ & $\begin{array}{l}100 . \\
0 \%\end{array}$ & $\begin{array}{l}100 . \\
0 \%\end{array}$ & $\begin{array}{l}100 . \\
0 \%\end{array}$ & $\begin{array}{l}100 . \\
0 \%\end{array}$ \\
\hline
\end{tabular}

\begin{tabular}{|l|l|l|}
\hline \multicolumn{2}{|l|}{ Chi-Square Tests } \\
\hline & Value & $\begin{array}{l}\mathrm{p} \\
\text { valu } \\
\mathrm{e}\end{array}$ \\
\hline $\begin{array}{l}\text { Pearson Chi- } \\
\text { Square }\end{array}$ & 2.477 & $\begin{array}{l}0.87 \\
1\end{array}$ \\
\hline $\begin{array}{l}\text { N of Valid } \\
\text { Cases }\end{array}$ & 48 & \\
\hline
\end{tabular}

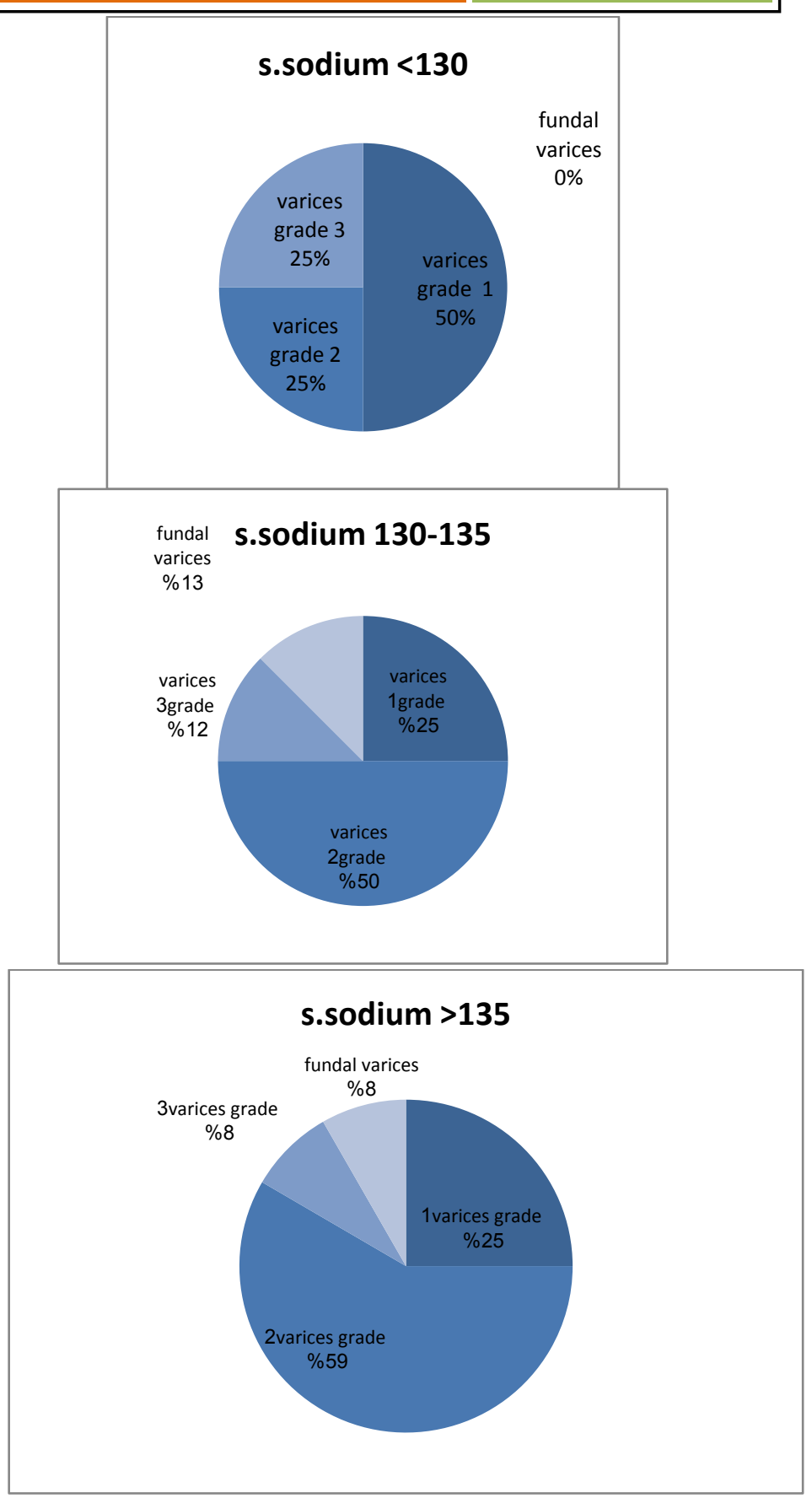

Figure (5) frequency distribution of serum sodium in different grades and types of varices.

Serum sodium in relation to presence and grade of encephalopathy

In the complicated group

1) 9 patients with mild encephalopathy [2 of them have s.sodium $<130 \mathrm{mmol} / \mathrm{l}, 6$ patients with s.sodium 130-135 $\mathrm{mmol} / \mathrm{l}$ and 1 patient with s.sodium $>135 \mathrm{mmol} / \mathrm{l}]$.

2) 6 cases with severe encephalopathy [4 patients with s.sodium $<130 \mathrm{mmol} / \mathrm{l}, 2$ patients with s.sodium $130-135 \mathrm{mmol} / \mathrm{l}]$.

$P$ value $=0.050$ i.e. significant correlation. 
Table (13) serum sodium in relation to encephalopathy.

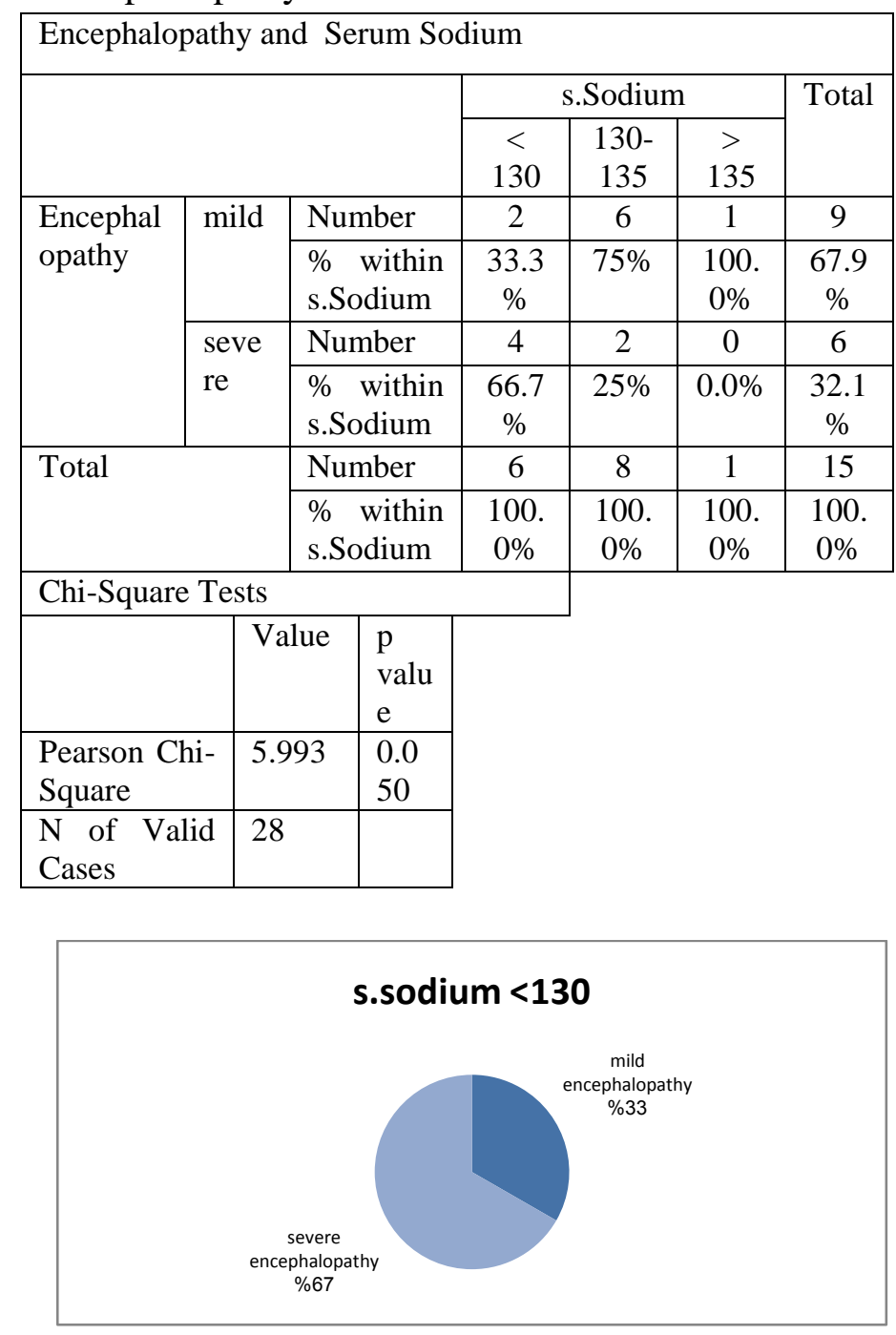
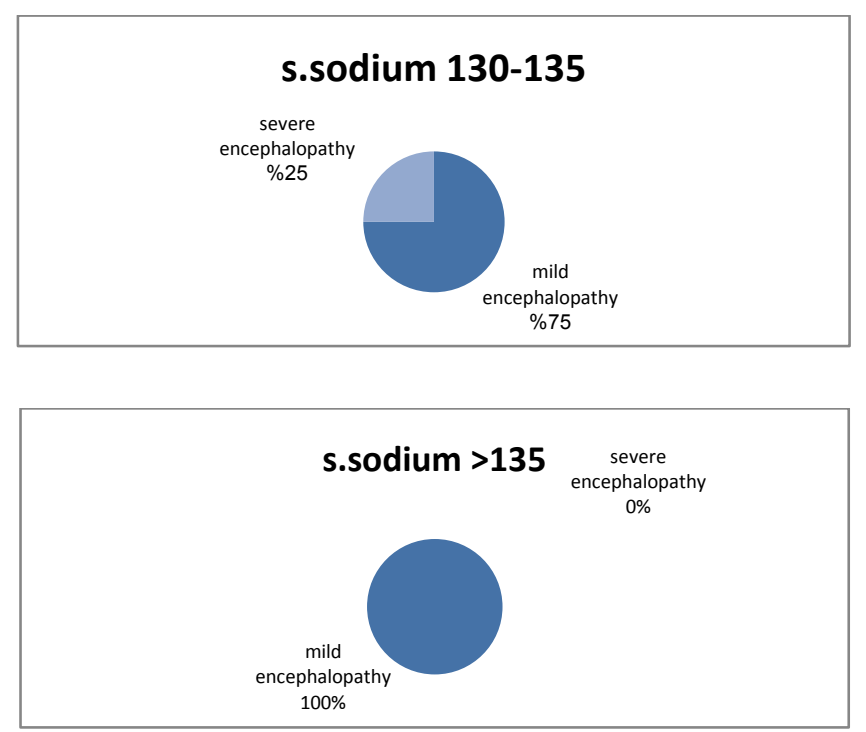

Figure (6) frequency distribution of serum sodium in encephalopathy.

\section{Serum sodium in relation to $S B P$ :}

\section{In the study group:}

12 cases had SBP [9 patients with s.sodium $<130$ $\mathrm{mmol} / \mathrm{l}, 3$ patients had s.sodium $130-135 \mathrm{mmol} / \mathrm{l}]$. $\mathrm{P}$ value $=0.0001$ i.e. $<0.05$ which is significant correlation.

Table (14) serum sodium in relation to SBP.

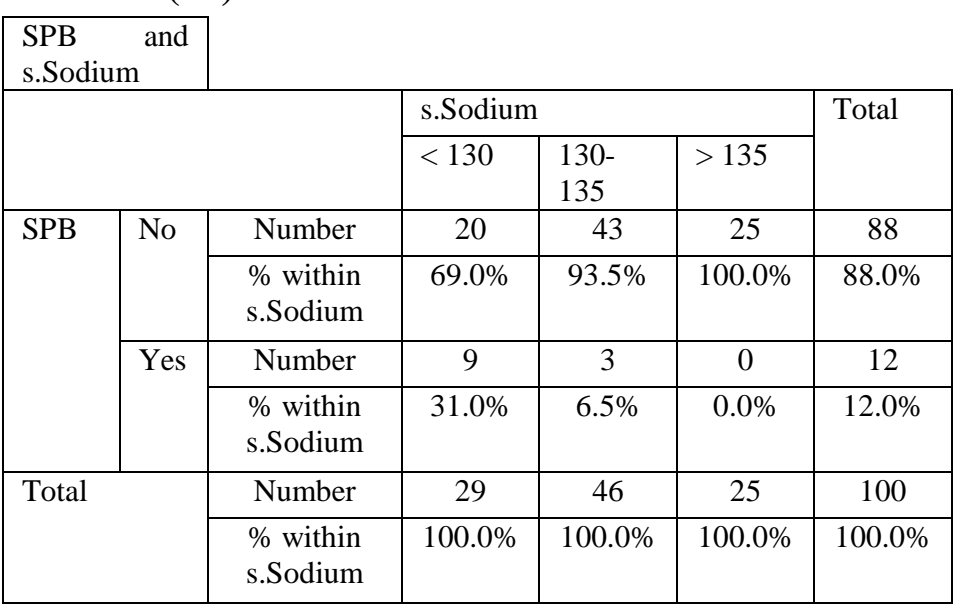

\begin{tabular}{|l|l|l|}
\hline \multicolumn{2}{|l|}{ Chi-Square Tests } \\
\hline & Value & $\begin{array}{l}\mathrm{p} \\
\text { value }\end{array}$ \\
\hline $\begin{array}{l}\text { Pearson Chi- } \\
\text { Square }\end{array}$ & 29.293 & 0.0001 \\
\hline $\begin{array}{l}\text { N of Valid } \\
\text { Cases }\end{array}$ & 200 & \\
\hline
\end{tabular}

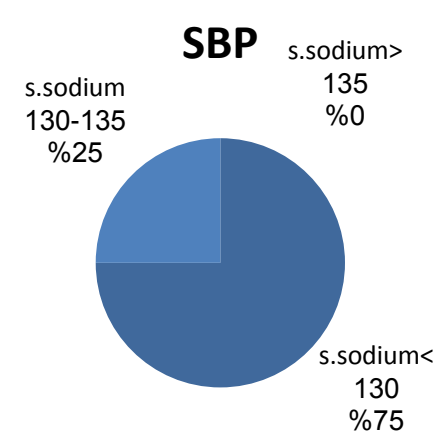

Figure (7) frequency distribution of serum sodium in SBP

\section{Serum sodium in relation to $\mathrm{HRS}$ :}

In the study group there were 16 patients with HRS:

- 4 patients had type 1 [3 patients with s.sodium $<130 \mathrm{mmol} / \mathrm{l}, 1$ patient with s.sodium130-135 mmol/1] .

- 8 patients with type 2 [6 patients with s.sodium <130 mmol/1 , 2 patients with s.sodium 130-135 mmol/l].

$P$ value $=0.0001$ i.e. $<0.05$ which is significant correlation. 
Table (15) serum sodium in relation to HRS.

\begin{tabular}{|c|c|c|c|c|c|c|}
\hline \multirow{3}{*}{\multicolumn{3}{|c|}{$\begin{array}{l}\text { HRS } \\
\text { s.Sodium }\end{array}$}} & & & & \multirow{3}{*}{ Total } \\
\hline & & & \multicolumn{3}{|c|}{ s.Sodium } & \\
\hline & & & $<130$ & $\begin{array}{c}130- \\
135\end{array}$ & $>135$ & \\
\hline \multirow[t]{6}{*}{ HRS } & \multirow[t]{2}{*}{ No } & Number & 20 & 43 & 25 & 88 \\
\hline & & $\begin{array}{l}\% \text { within } \\
\text { s.Sodium }\end{array}$ & $69 \%$ & $\begin{array}{c}93.5 \\
\%\end{array}$ & $100 \%$ & $\begin{array}{c}92.0 \\
\%\end{array}$ \\
\hline & \multirow{2}{*}{$\begin{array}{l}\text { type } \\
1\end{array}$} & Number & 3 & 1 & 0 & 4 \\
\hline & & $\begin{array}{l}\% \text { within } \\
\text { s.Sodium }\end{array}$ & $\begin{array}{c}10.3 \\
\%\end{array}$ & $2.2 \%$ & $0.0 \%$ & $4.0 \%$ \\
\hline & \multirow{2}{*}{$\begin{array}{l}\text { type } \\
2\end{array}$} & Number & 6 & 2 & 0 & 8 \\
\hline & & $\begin{array}{l}\% \text { within } \\
\text { s.Sodium }\end{array}$ & $\begin{array}{c}20.7 \\
\%\end{array}$ & $4.3 \%$ & $0.0 \%$ & $4.0 \%$ \\
\hline \multirow{2}{*}{\multicolumn{2}{|c|}{ Total }} & Number & 29 & 46 & 25 & 100 \\
\hline & & $\begin{array}{l}\% \text { within } \\
\text { s.Sodium }\end{array}$ & $\begin{array}{c}100.0 \\
\%\end{array}$ & $\begin{array}{c}100.0 \\
\%\end{array}$ & $\begin{array}{c}100.0 \\
\%\end{array}$ & $\begin{array}{c}100.0 \\
\%\end{array}$ \\
\hline
\end{tabular}

Chi-Square Tests

\begin{tabular}{|l|l|l|}
\hline & Value & $\begin{array}{l}\mathrm{p} \\
\text { value }\end{array}$ \\
\hline $\begin{array}{l}\text { Pearson } \\
\text { Chi-Square }\end{array}$ & 36.36 & 0.00 \\
\hline $\begin{array}{l}\text { N of Valid } \\
\text { Cases }\end{array}$ & 200 & 01 \\
\hline
\end{tabular}

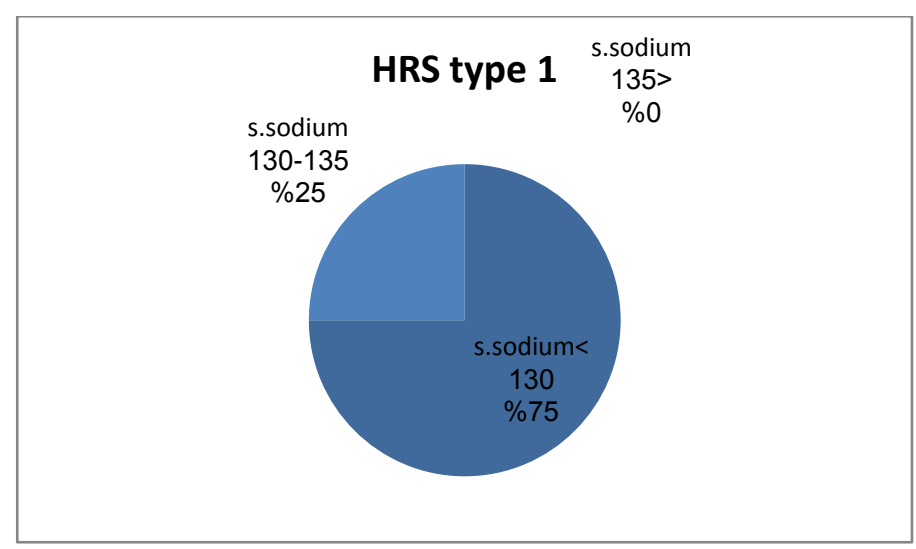

\section{Discussion}

Cirrhosis is defined histologically as a diffuse hepatic process characterized by fibrosis and the conversion of normal liver architecture into structurally abnormal nodules. The progression of liver injury to cirrhosis may occur over weeks to years. ${ }^{(1)}$.

Cirrhosis resulted in 1.2 million deaths in 2013, up from 0.8 million deaths in 1990.Of these, alcohol caused 384,000, hepatitis C caused 358,000 , and hepatitis B caused 317,000. Cirrhosis is the 12th leading cause of death in the United States, accounting for nearly 32,000 deaths each year. More men die of cirrhosis than women.
Importantly, chronic liver disease and cirrhosis are the seventh leading cause of death in the United States in individuals between 25 and 64 years of age. Because chronic liver disease affects people in their most productive years of life, it has a significant impact on the economy as a result of premature death, illness, and disability, in the developed countries ALD, HCV and NASH are the most significant causes of cirrhosis ${ }^{(10)}$.

Normal serum sodium Ranges 135 - 145 mEq/L ,it is the Chief extracellular cation. Its homeostasis is vital to the normal function of cells. Normal serum sodium levels are between 135 and $145 \mathrm{mEq} / \mathrm{L}$. Hyponatremia is defined as a serum level of less than $135 \mathrm{mEq} / \mathrm{L}$ and is considered severe when the serum level is below $125 \mathrm{mEq} / \mathrm{L}$. ${ }^{(11)}$

Diseases such as cirrhosis may cause hyponatremia by nature of an increased production of AVP. In cirrhosis, splanchnic vasodilation leads to arterial underfilling which unloads high-pressure baroreceptors that stimulate a nonosmotic hypersecretion of AVP, leading to solute-free water retention and dilutional hyponatremia ${ }^{(12)}$.

Hyponatremia is a frequent complication of advanced cirrhosis related to an impairment in the renal capacity to eliminate solute-free water that causes a retention of water that is disproportionate to the retention of sodium, thus causing a reduction in serum sodium concentration and hypo-osmolality. The main pathogenic factor responsible for hyponatremia is a nonosmotic hypersecretion of arginine vasopressin AVP (or antidiuretic hormone) from the neurohypophysis related to circulatory dysfunction. Hyponatremia in cirrhosis is associated with increased morbidity and mortality. There is evidence suggesting that hyponatremia may affect brain function and predispose to hepatic encephalopathy. Hyponatremia also represents a risk factor for liver transplantation as it is associated with increased frequency of complications and impaired shortterm survival after transplantation. ${ }^{(13)}$ 
In our work we tried to explore the prevalence of hyponatremia and its complications in Egyptian patients hospitalized with liver cirrhosis.

In a review of a previously conducted multi-center study in overseas countries, 997 patients with liver cirrhosis and concurrent ascites, who were under the care of hepatologists in hepatology outpatient clinics, were assigned to three groups based on serum sodium concentration, in a manner similar to that of the current study. The prevalence of hyponatremia at a serum sodium $\leq 135 \mathrm{mmol} / \mathrm{L}$ was $49.4 \%$. Concurrent complications such as severe ascites, impaired renal function, hepatic encephalopathy, spontaneous bacterial peritonitis and hepatorenal syndome, except for gastrointestinal bleeding, occurred with a higher probability in cases of severe hyponatremia (serum sodium $\leq 130 \mathrm{mmol} / \mathrm{L})^{(4)}$.

In a study with 156 patients hospitalized with liver cirrhosis, the prevalence of hyponatremia, based on a serum sodium concentration $\leq 130 \mathrm{mmol} / \mathrm{L}$, was $29.8 \%$, and hyponatremia was significantly correlated with infection and ascites ${ }^{(14)}$.

In the current study, conducted in patients hospitalized with complications due to liver cirrhosis, the prevalence of hyponatremia at a serum sodium concentration $<135 \mathrm{mmol} / \mathrm{L}$ was $75 \%$, and that of severe hyponatremia at a serum sodium concentration $<130 \mathrm{mmol} / \mathrm{L}$ was $29 \%$.

These results were similar to the overseas reports. In fact, the severity of hyponatremia, particularly at serum sodium concentrations $<130 \mathrm{mmol} / \mathrm{L}$, corresponded to higher risks for developing ascites, spontaneous bacterial peritonitis, degree of hepatic encephalopathy and the the incidences of hepatorenal syndrome compared with the risks in patients with a serum sodium $>136 \mathrm{mmol} / \mathrm{L}$. In agreement with previous reports, serum sodium concentration was not associated with the presence of varices.

Currently, many ongoing studies are examining the pathophysiology of hyponatremia accompanied by liver cirrhosis, and dilutional hyponatremia has been considered the most plausible pathophysiology). NO is increased in patients with portal hypertension. Owing to the vasodilatory effect of increased $\mathrm{NO}$ and the lower effective circulating blood volume in these patients, anti-diuretic hormone secretion is facilitated with the mediation of baroreceptors, despite the presence of a hypo-osmotic environment. The increased level of anti-diuretic hormones lowers solute-free water excretion, leading to dilutional hyponatremia ${ }^{(15)}$.

In our current study patients were classified into groups according the Child Pugh classification as 5 patients of the complicated group $(5.0 \%)$ were Child-Pugh A, 34 were B (34\%) and 61 were C $(60 \%)$, while in the uncomplicated (control) group the fifty persons were child A (100\%), no one were child B or child C.

In the current study, the risks for complications such as severe ascites, spontaneous bacterial peritonitis and hepato renal syndrome were increased at low serum sodium concentrations. These complications are believed to occur because of increased body fluid resulting from the impairment of solute-free water excretion. Hepatic encephalopathy occurs as a result of severe hepatic dysfunction. In cases in which hyponatremia is concurrently present, however, Hepatic encephalopathy has been shown in several studies to be worsened by the presence of hyponatraemia. Hyponatraemia with serum sodium $\leq 130 \mathrm{mEq} / \mathrm{L}$ is one of several predictive factors, along with a history of encephalopathy, serum creatinine and bilirubin, for the development of overt hepatic encephalopathy in a one year study period. Hyponatraemia was the strongest predictive factor with an HR of 10.5 (95\% CI: 5.4-20.3) for development of overt encephalopathy in one year, and was also found to be correlated with decreased levels of the brain osmolyte, myo-inositol, supporting a role for cerebral intracellular water shifts and astrocyte swelling in the development of hepatic encephalopathy. ${ }^{(16)}$.

The presence and severity of varices did not correlate with serum sodium concentration in the present study, because development of varices depends on not the excess of body water but the histological changes such as the compression of 
venules by regenerating nodules, perisinusoidal obstruction resulting from periportal inflammation, or fibrosis and decreased sinusoidal elasticity and diameter caused by collagen deposition in the space of Disse. Further studies are needed to demonstrate a significant relationship between the serum sodium concentration and the above histological changes.

Treatment options for patients admitted with hyponatraemia and cirrhosis are limited. The first step in management should be to identify and correct the underlying cause of hyponatraemia, which includes holding diuretics and addressing gastrointestinal losses. Patients who are found to be hypovolemic with correlate orthostasis or prerenal azotemia should be adequately resuscitated with intravenous crystalloid or albumin infusion. It is important to recognize that the cirrhotic patient with true hypovolemic hyponatraemia without ascites or oedema is rare. Free water restriction to less than 1.0-1.5 L/day has become standard practice in treating patients with hypervolemic hyponatraemia in cirrhosis and may have some anecdotal benefit in preventing a further drop in serum sodium ${ }^{(17)}$

Trials including fluid-restricted control groups (<1.5 L/day) have demonstrated no significant benefit in free water clearance or serum sodium . This method has not been proven in clinical trials, is often very difficult to monitor and many patients cannot realistically adhere to this restriction. ${ }^{(18)}$

Severe hyponatraemia with serum sodium level $<120 \mathrm{mEq} / \mathrm{L}$ is uncommon in the cirrhotic population, occurring in less than $1.2 \%$ of patients. ${ }^{(19)}$

In the setting of severe hyponatraemia with symptoms such as seizure, one must consider correction to a safe level, so as to prevent recurrence and neurological injury. This is the one situation where the administration of hypertonic saline is advised, with care taken to avoid overly rapid correction. Serum sodium increases of $<10$ $\mathrm{mmol} / \mathrm{L}$ in 24 hours and $<18 \mathrm{mmol} / \mathrm{L}$ in 48 hours are recommended. The use of hypertonic saline in cirrhotic patients can lead to worsening ascites and oedema secondary to the sodium avid state that exists in the nephron, and should be used only in acute situations. ${ }^{(20)}$

Albumin infusion can be considered as a treatment for hyponatraemia in cirrhosis. The available data are limited and include a small number of patients with very short-term follow-up, but suggest a benefit that needs to be explored in larger, randomized trials. ${ }^{(21)}$

A randomized pilot study in 24 patients admitted with serum sodium $<130 \mathrm{mmol} / \mathrm{L}$ found that albumin significantly improved serum sodium levels, compared with matched controls treated with fluid restriction, with a mean increase of 9 $\mathrm{mmol} / \mathrm{L}$. There was also a significant increase, compared with controls, in free water clearance and serum vasopressin levels in patients treated with albumin. This finding suggests that albumin may contribute to the improvement of circulatory dysfunction and decrease the non-osmotic release of arginine vasopressin (AVP). ${ }^{(21)}$

The introduction of a new drug class, termed 'vaptans', was heralded by excitement over their potential benefit in cirrhosis-related hyponatraemia. These medications act as direct antagonists of the V2 receptor in the collecting tubule of the nephron, and significantly increase free water clearance. Tolvaptan (Samsca) is currently the only orally administered V2R antagonist that is approved for use in the United States. Lixivaptan and sativaptan have also been studied in cirrhosis and hyponatraemia.

The efficacy of tolvaptan in raising serum sodium level was studied in two randomized, placebo controlled, double blind phase 3 trials (Study of Ascending Levels of Tolvaptan in Hyponatraemia 1 and 2 [SALT-1 and SALT-2]). ${ }^{(12)}$

All patients had dilutional hyponatraemia with serum sodium $\leq 135 \mathrm{mEq} / \mathrm{L}$, with $50 \%$ of patients classified as markedly hyponatraemic with serum sodium levels $<130 \mathrm{mEq} / \mathrm{L}$. The population was not limited to patients with cirrhosis $(22.4 \%$ SALT-1 and 30.5\% SALT-2) but included those with hyponatraemia related to heart failure and the syndrome of inappropriate anti-diuretic hormone (SIADH). All patients were hospitalized and were 
randomized to tolvaptan $15 \mathrm{mg}$ daily or placebo, with up-titration of dosing to a maximum of 60 $\mathrm{mg} / \mathrm{d}$ in those who failed to respond to lower doses. Serum sodium improved and reached normal levels in a significantly larger number of patients in the tolvaptan group, compared with placebo $(P<0.001)$. The most common sideeffects were thirst and dry mouth. An important subgroup analysis of the patients with cirrhosis revealed a significant increase in free water clearance, associated with weight loss, without renal impairment and normalization of serum sodium to $>135 \mathrm{mEq} / \mathrm{L}$ in $41 \%$ of patients at day 4 and $33 \%$ at day 30. A secondary analysis also found a significant improvement in health-related quality of life scores in patients treated with tolvaptan. ${ }^{(22)}$.

Hyponatraemia reliably recurs upon discontinuation of treatment. That said, recent concerns over the safety of tolvaptan were raised by a subanalysis of a large, multicentre trial that evaluated the use of tolvapatan in patients with polycystic kidney disease. Patients developed a significant elevation of liver enzymes; thus the FDA placed a 'black box' warning on the drug, limiting its use on patients with liver disease. ${ }^{(23)}$.

Long-term data on the use of vaptans in cirrhosis is limited but, in trials of SIADH, both satavaptan and tolvaptan had lasting effects and maintained near-normonatremia when continued for one year. (24)

Satavaptan and lixivaptan have been evaluated in several trials of hyponatraemia, including in cirrhotic patients, who showed an improvement in hyponatraemia and no serious adverse events compared with placebo. Satavaptan was shown to maintain efficacy throughout a one-year study period in a cohort of 73 cirrhotic patients treated with drug vs placebo, with no significant increase in adverse events. ${ }^{(13)}$.

Unfortunately, the use of satavaptan was associated with an increased mortality in one of the studies - though not in the other two - and the drug was withdrawn from development. The reason for this increased mortality could not be elucidated. It is not known if this increased mortality during long-term treatment is a class effect or exclusively related to satavaptan.

Overall, the vaptans have not been shown to improve outcomes in cirrhosis. A recent metaanalysis evaluated outcomes in 2266 patients from 12 randomized trials of tolvaptan, satavaptan and lixivaptan. The primary outcome measure was mortality and secondary outcomes included - but were not limited to-complications of cirrhosis and mobilization of ascites. ${ }^{(25)}$.

The effects of vaptans on control of ascites and prevention of hepatic encephalopathy has been evaluated in several trials. In a study of 1200 patients combined from three randomized trials with (a) uncomplicated ascites, (b) difficult-totreat ascites with- and (c) without diuretics, there was no significant benefit from satavaptan in preventing worsening of ascites or reducing the number of large volume paracentesis. Satavaptan did improve serum sodium level when compared with placebo and also showed a small but significant increase in time to first large-volume paracentesis $(\mathrm{RR}=0.72 ; 95 \% \mathrm{CI}: 0.53-0.98)$. ${ }^{\text {(26) }}$

A meta-analysis of this same patient population failed to show a significant decrease in the number of hepatic encephalopathy episodes with satavaptan. ${ }^{(27)}$.

A recent trial in Japan randomized 164 patients to receive either tolvaptan or placebo as add-on therapy to diuretics, with the primary end-point of weight change at 7 days. There was a significant reduction in weight in the tolvaptan group, compared with placebo $(-1.95 \mathrm{~kg}$ vs $-0.44 \mathrm{~kg} ; P<$ 0.0001 ), and this benefit held true, even in patients with serum albumin $<2.5 \mathrm{~g} / \mathrm{dL}$. ${ }^{(28)}$.

In summary there is conclusive evidence that serum hyponatremia has strong correlation to the severeity of complication of liver cirrhosis.

Hyponatraemia is a commonly encountered problem in patients with end-stage liver disease. Low serum sodium is a poor prognostic indicator in both the pre- and post-transplant patient population and has been shown to increase the risk of early mortality and complications including ascites, infection, renal failure, and encephalopathy. The treatment options for hyponatraemia 
are limited and are currently based on adequate free water restriction, cessation of diuretics, albumin infusion and potentially the use of vaptans in the short term on a patient-by-patient basis.

The vaptans may be of potential benefit in the peri-transplant period; however, drugs currently on the market should not be used for this indication in patients with cirrhosis. This issue therefore needs to be further evaluated with new vaptan agents in controlled trials. Liver transplantation remains the only definitive treatment for end-stage liver disease complicated by hyponatraemia.

\section{Conclusion and Recommendations}

Cirrhosis is the end result of chronic liver injury from a variety of causes and it was found that hyponatremia is a common abnormal finding in approximately $57 \%$ of hospitalized patients with chronic liver disease and in $40 \%$ of the outpatients with liver disease.

The aim of the present work is to study the association between serum sodium level and the severity of complications in liver cirrhosis.

150 patients were enrolled in the study ,100 patients of them with complicated liver cirrhosis and 50 patients with uncomplicated chronic liver disease served as control, Patients with liver cirrhosis [diagnosis was limited to cases with approved liver cirrhosis by clinical findings, laboratory and ultrasonography] randomly selected from Bani-suef university hospital based on severity of complications at the time of admission, Patients with hepatocellular carcinoma or other malignancy presented on admission and during the follow up,or have other major organ failure, also patients taking antiviral drugs were excluded.

Patient were classified into groups according the previous Child Pugh classification as 5 patients of the complicated group (5.0\%) were Child-Pugh A, 34 were B (34\%) and 61 were C $(61 \%)$, while in the control group 50 persons were child A (100\%) and no one was classified as child B or $\mathrm{C}$.
Assessing serum sodium profile among the two groups revealed a highly significant difference between the two studied groups in all the previous parameters $(\mathrm{P}<0.001)$ and revealed the following facts:

- As regards serum sodium difference between control and complicated group it was found that the difference between the 2 groups is statistically significance $\mathrm{p}$ value $=0.0001$

- As regards the decrease in serum sodium level in relation to the child classification it was found highly significant correlation $\mathrm{p}$ value $=0.004$

- As regards the decrease in serum sodium level in relation to the degree of ascites, there was strong correlation, $\mathrm{P}$ value $=0.0001$, which is found to be highly significant correlation.

- As regards the decrease in serum sodium level and SBP, there was strong correlation, $p$ value $=0.0001$

- As regards the decrease in serum sodium level and the degree of encephalopathy, there was significant relationship, $\mathrm{p}$ value $=0.050$.

- As regards the decrease in serum sodium level and the HRS, there was significant correlation, $p$ value $=0.0001$

- As regards the decrease in serum sodium level and degree of esophageal varices or fundal varices, there was no significant relationship, $\mathrm{p}$ value $=0.871$

It is therefore concluded that Hyponatremia, especially serum levels $<130 \mathrm{mmol} / \mathrm{L}$, may indicate the existence of severe complications associated with liver cirrhosis.

Further prospective studies are needed to determine the significance of hyponatremia as a predictive factor in the incidence of possible complications.

One limitation of the current study was that it did not assess the effect of serum sodium concentration on the risks for developing complications but simply examined the concurrent presence of complications and sodium levels. 
Further prospective studies are needed to determine the significance of hyponatremia as a predictive factor in the incidence of possible complications.

\section{References}

1. Wolf DC. Cirrhosis. Medscape website. http://emedicine.medscape.com/article/185 856-overviewExternal Link Disclaimer. Updated August 5, 2013. Accessed February 6, 2014.W

2. Murphy SL, Xu J, Kochanek KD. Deaths: final data for 2010. Centers for Disease Control and Prevention website.

3. Shepard CW, Finelli L, Fiore AE, Bell BP. Epidemiology of hepatitis B and hepatitis $B$ virus infection in United States children. Pediatr Infect Dis J. 2005;24:755-760

4. Angeli P, Wong F, Watson $\mathrm{H}$, Ginès $\mathrm{P}$, CAPPS Investigators ,Hepatology. 2006

5. Hammer, edited by Stephen J. McPhee, Gary D. (2010). Pathophysiology of disease: an introduction to clinical medicine (6th ed.). New York: McGrawHill Medical. pp. Chapter 14: Liver Disease. Cirrhosis. ISBN 9780071621670.

6. De Franchis R, Dell'Era A. Non-invasive diagnosis of cirrhosis and the natural history of its complications. Best Pract Res Clin Gastroenterol 2007;21:3-18....

7. Iredale JP, Guha IN. The evolution of cirrhosis. In: Textbook of hepatology from basic science to clinical practice. 3rd edition. Edited by Rodés J, Benhamou J-P, Blei A, Reichen J, Rizzetto M. Oxford, Blackwell Publishing 2007:583-589

8. Guevara M, Baccaro ME, Torre A, et al. Hyponatremia is a risk factor of hepatic encephalopathy in patients with cirrhosis: a prospective study with time-dependent analysis. Am J Gastroenterol 2009;104:1382-89.

9. Conn, HO, Leevy, CM, Vlahcevic, ZR, et al. Comparison of lactulose and neomycin in the treatment of chronic portal-systemic encephalopathy. Gastroenterology 1977; 72:573.

10. Wynn T. Cellular and molecular mechanisms of fibrosis. J Pathol 2008; 214:199-210..

11. MayoClinic. Retrieved 2010-09-01.

12. Schrier RW. Water and sodium retention in edematous disorders: role of vasopressin and aldosterone. Am J Med 2011; 119(suppl 1):S47-S53

13. Ginés P and Cardenas A, (2008): The management of ascites and hyponatremia in cirrhosis. Semin Liver Dis. Feb ; 28 (1): 43-58.

14. Borroni G, Maggi A, Sangiovanni A, Cazzaniga M, Salerno F Dig Liver Dis. 2009 Oct; 32(7):605-10.

15. Gine`s P, Arroyo V, Rode's J, Schrier RW, eds. Ascites and Renal Dysfunction in Liver Disease: Pathogenesis, Diagnosis and Treatment. 2nd ed. Oxford: Blackwell Science; 2005:305-314

16. Guevara M, Baccaro ME, Torre A, et al. Hyponatremia is a risk factor of hepatic encephalopathy in patients with cirrhosis: a prospective study with time-dependent analysis. Am J Gastroenterol 2009; 104:1382-89.

17. EASL clinical practice guidelines for HFE hemochromatosis. J Hepatol. 2010;53:322.--; EASL Clinical Practice Guidelines. Wilson's disease. J Hepatol. 2012;56:671685.

18. Gerbes AL, Gu“ lberg V, Gine`s P, et al. The VPA Study Group. Therapy of hyponatremia in cirrhosis with a vasopressin receptor antagonist: a randomized double-blind multicenter trial. Gastroenterology 2003;124:933-939

19. Runyon BA. Management of adult patients with ascites due to cirrhosis: an update. Hepatology. 2009;49:2087-2107.

20. Verbalis JG, Goldsmith SR, Greenberg A, et al. Hyponatremia treatment guidelines 2007: expert panel recommendations. Am J Med 2010;120 11 Suppl 1:S1-21. 
21. Jalan R, Mookerjee R, Cheshire L, et al. Albumin infusion for severe hyponatremia in patients with refractory ascites: a randomized clinical trial. J Hepatol 2009; 46:232A

22. Cárdenas A, Ginès $\mathrm{P}$, Marotta $\mathrm{P}$, et al. Tolvaptan, an oral vasopressin antagonist, in the treatment of hyponatremia in cirrhosis. J Hepatol 2014;56:571-78.

23. Torres VE, Chapman AB, Devuyst O, et al. TEMPO 3:4 Trial Investigators. Tolvaptan in patients with autosomal dominant polycystic kidney disease. $\mathrm{N}$ Engl J Med 1012;367:2407-18.

24. Soupart A, Coffernils M, Couturier B, et al. Efficacy and tolerance of urea compared with vaptans for long-term treatment of patients with SIADH. Clin J Am Soc Nephrol 2012;7:742-47.

25. Dahl E, Gluud LL, Kimer N, et al. Metaanalysis: the safety and efficacy of vaptans (tolvaptan, satavaptan and lixivaptan) in cirrhosis with ascites or hyponatremia. Aliment Pharmacol Ther 2012;36:619-26.

26. Wong F, Watson H, Gerbes A, et al. Satavaptan Investigators Group. Satavaptan for the management of ascites in cirrhosis: efficacy and safety across the spectrum of ascites severity. Gut 2012;61:108-16.

27. Watson H, Jepsen P, Wong F, et al. Satavaptan treatment for ascites in patients with cirrhosis: A meta-analysis of effect on hepatic encephalopathy development. Metab Brain Dis 2013;28:301-5.

28. Sakaida I, Kawazoe S, Kajimura K, et al. ASCITES-DOUBLEBLIND Study Group. Tolvaptan for improvement of hepatic edema: A phase 3, multicenter, randomized, double-blind, placebocontrolled trial. Hepatol Res 2013. Apr 3. Epub ahead of print. 